a gradient of 1 in 6, skis show a substantial saving of energy over snowshoes. Carrying a $30 \mathrm{~kg}$. load in a rucksack adds $40 \%$ to a man's energy expenditure, but uses $15 \%$ less energy than pulling the same load on a sledge weighing $8 \mathrm{~kg}$. Nevertheless the sledge may still be preferable as it saves fatigue of the back muscles. This assertion is certainly well-founded; the continual heavy load on the muscles of the back appears to impede the circulation and cause pain.

Christensen and Högberg point out that in ski-racing the very high energy output places a considerable strain on the heart and circulatory system. They record many pulse-rates of 220-60 in youths at the end of a $5 \mathrm{~km}$. race, and the oxygen intake values in these experiments are nearly the highest ever recorded.

The authors conclude that ski-ing is the most economical method of travelling on snow surfaces, whether they be hard or soft. Anyone intending to make a long journey on skis would do well, in planning food supplies, to consider these figures for energy expenditure.

B. H. C. MatThewS

\title{
A GREENHOUSE IN THE ANTARCTIC
}

[The following note describes an experimental greenhouse used at Stonington Island, Marguerite Bay (Falkland Island Dependencies Survey, Base.E), in 1946-47.]

In designing a greenhouse for use in the Antarctic, allowances must be made for such hazards as excessive snowfall, high winds, and very low temperatures. It should not be forgotten that snow drifts may enable sledge dogs to roam on to the roof.

At Stonington Island it was therefore decided to build a "lean-to", the only entrance being through the wall of the hut directly into the greenhouse. Thus, on opening the greenhouse door, air from a comparatively warm room would enter the greenhouse rather than cold air from outside. The greenhouse was built against one wall of the workshop, which was heated by a slow-combustion anthracite stove, and fitted with a boiler and set of $\mathbf{2}$ inch pipes for heating the greenhouse. The stove was placed in the workshop opposite the entrance to the greenhouse. The other end of the water system was an open-ended 10-gallon copper tank. The water supply was maintained by adding ice to this tank. If at any time the heat became excessive, hot water could be run off and ice added.

The greenhouse itself was $6 \mathrm{ft}$. long by $4 \mathrm{ft}$. wide by $6 \mathrm{ft}$. high, sloping down to $4 \mathrm{ft} .6 \mathrm{in}$. The foundations were elongations of the main floor beams. The bottom $2 \mathrm{ft}$. of wall consisted of tongued and grooved weather boarding pinned to a framework of a 2 by 4 in. timber. The superstructure rested on this supporting wall. The framework was substantial and allowed of double glazing with a $2 \frac{1}{2}$ in. air space between the layers of glass. The spans of glass in the roof and sides were all single sheets, unlike those in temperate climates where small overlapping sheets of glass are used. This was to prevent thaw water getting under the overlap with subsequent freezing causing a break. The glass 


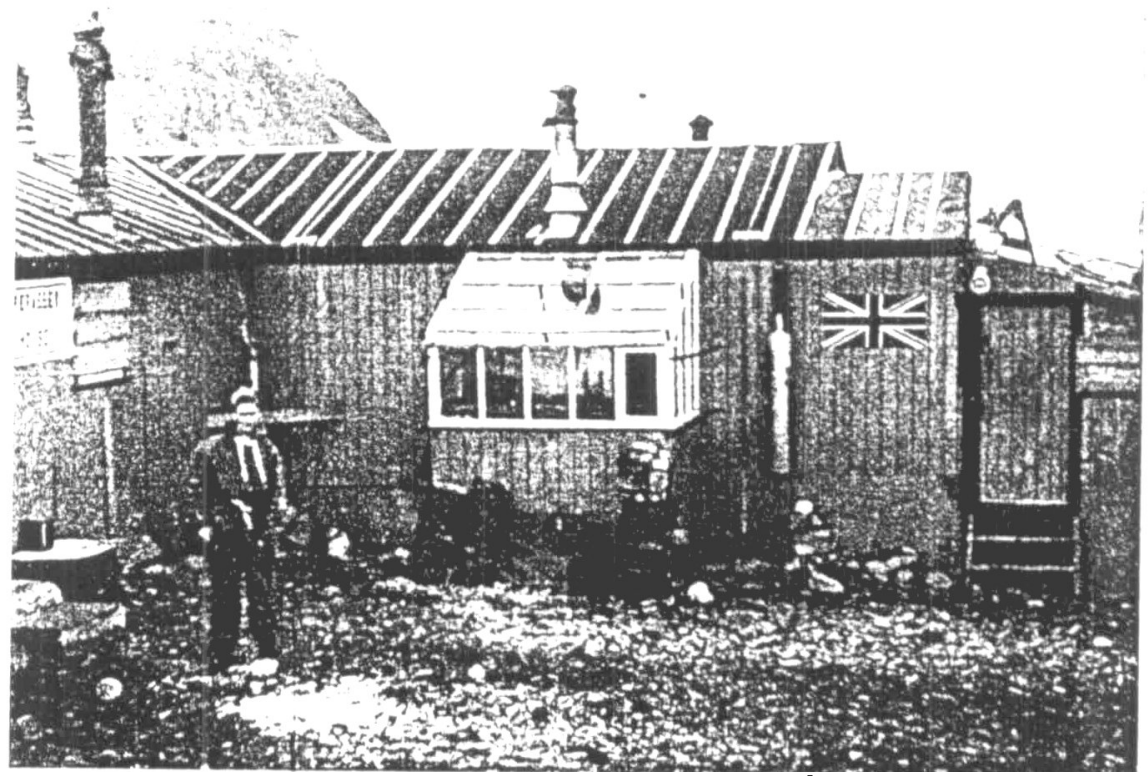

The greenhouse on the north wall of the hut at Stonington Island, lat. $68^{\circ} 7^{\prime} \mathrm{S}$., long. $66^{\circ} 30^{\prime} \mathrm{W}$.

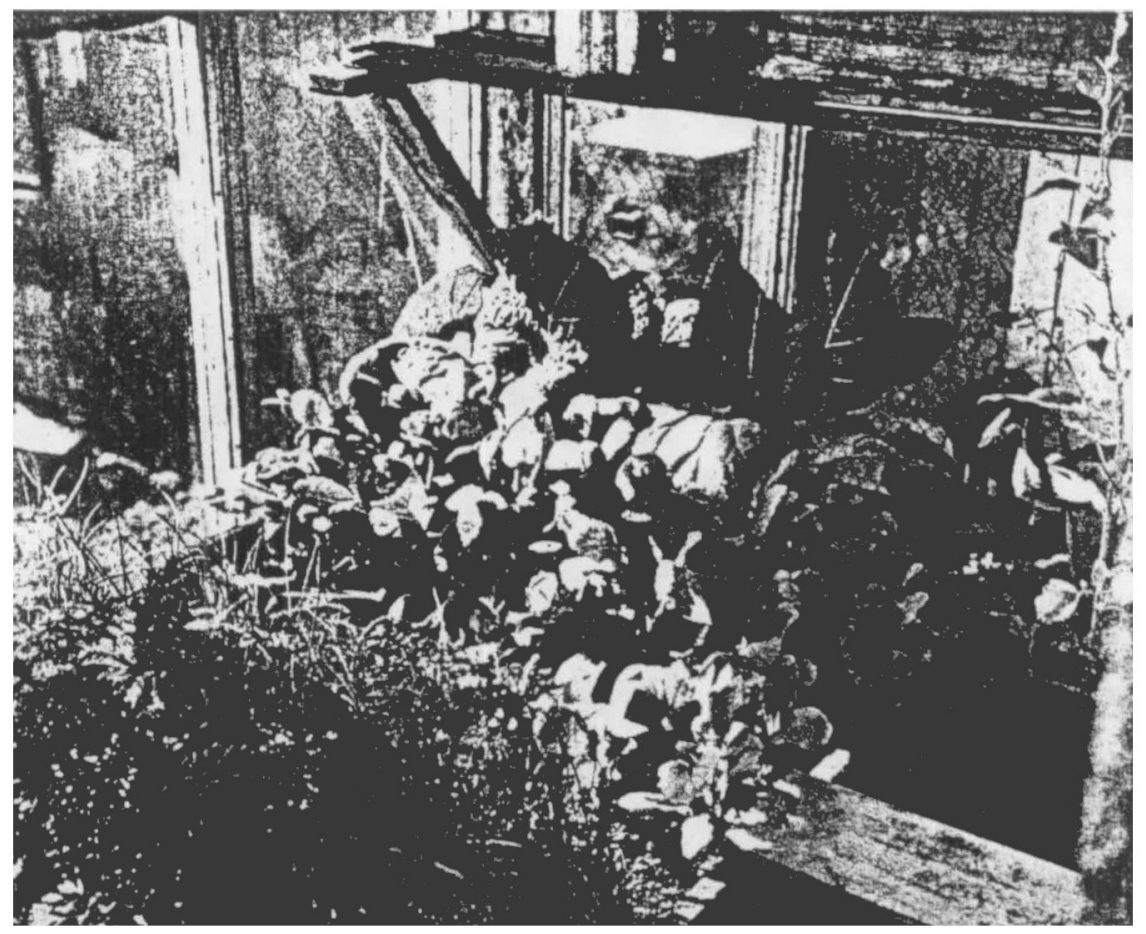

Part of the interior of the greenhouse, showing carrots, spring onions, radishes and cabbages.

Falkitand Island Dependencies Storvey photographs 
and woodwork were first thoroughly dried, and glazing was carried out in sunny weather to ensure that as little moisture as possible was left in the air space. The object of this was to prevent fogging with consequent diminution of light.

The low wooden walls and the floor were lined with aluminium foil to reflect heat back into the greenhouse. A sheet of uncovered foil was experimentally spread over the back wall of the greenhouse and the reflected light and heat were most noticeable. In summer this reflection proved excessive, but in the darker periods of the year proved very useful.

On completion of the glazing, strong metal angle brackets were screwed to the outside of the framework to support horizontal strips of metal 6 in. clear of the glass. The glass was then protected by stretching $\frac{1}{2}$ in. mesh wire netting over the metal bars. The wire netting was fastened to the bars with simple clips so that sections could readily be removed when it became necessary to clean snow, ice or dirt from the glass. During the winter months repeated digging was necessary to prevent the house from being snowed under. Experience showed that it would have been advisable to place the greenhouse at the gable end of the main building, as in this position less snow would have avalanched on to the lean-to roof, and thaw water from the roof of the hut would also have bcen avoided.

Despite the greatest care a sheet of glass may crack and allow water to enter the air space. This water can be removed by drilling a fine hole through the wooden framcwork into the bottom of the affected air space. The water can then be sucked out with a hypodermic syringe and needle, and the hole plugged. It was found that cracked glass could be sealed adequately with Canada Balsam.

As no soil was available a full range of salts for hydroponic gardening was brought south and suitable solutions were made up from these. Volcanic ash and sand were used instead of soil and saturated with the prepared solutions. Flowers and vegetables were successfully grown by this method. The specd of growth during the summer was remarkable. On clear sunny days some shade was necessary.

Pansies did well, and gave a prolonged and delightful show. Lettuce and radish also flourished and cress grew rampantly. Bulbs, it was discovered, should be carefully packed and watched during the journey to avoid excessive frost before planting.

The greenhouse should if possible be given a northerly aspect in the Antarctic, but this must depend on more serious considerations such as direction of drift, size of site available and special expedition requirements.

E. W. BINGHAM 